The health monitoring of a prestressed concrete beam by using fiber Bragg grating sensors

This article has been downloaded from IOPscience. Please scroll down to see the full text article.

2004 Smart Mater. Struct. 13712

(http://iopscience.iop.org/0964-1726/13/4/008)

The Table of Contents and more related content is available

Download details:

IP Address: 140.112.113.225

The article was downloaded on 13/02/2009 at 09:45

Please note that terms and conditions apply. 


\title{
The health monitoring of a prestressed concrete beam by using fiber Bragg grating sensors
}

\author{
Yung Bin Lin ${ }^{1}$, Kuo Chun Chang ${ }^{1}$, Jenn Chuan Chern ${ }^{1}$ and \\ Lon A Wang ${ }^{2}$ \\ ${ }^{1}$ Department of Civil Engineering, National Taiwan University, Taipei 10617, Taiwan \\ ${ }^{2}$ Department of Electrical Engineering and Graduate Institute of Electro-Optical \\ Engineering, National Taiwan University, Taipei 10617, Taiwan \\ E-mail: yblin@ncree.gov.tw, ciekuo@ntu.edu.tw,jcchern@ntu.edu.tw and lon@ntu.edu.tw
}

Received 22 October 2002, in final form 12 February 2004

Published 18 May 2004

Online at stacks.iop.org/SMS/13/712

DOI: $10.1088 / 0964-1726 / 13 / 4 / 008$

\begin{abstract}
This paper presents the complete test results of a prestressed concrete (PC) beam, including the hydration temperature of the hardening process, the behavior of the PC beam under sustained loading and assessment of damage, such as the locations of cracks and their corresponding depth. Hydration temperatures during the hardening process were determined using fiber Bragg grating (FBG) sensors, while the behavior of the PC beam, under sustained loading, was evaluated and compared using conventional sensors as well as FBG sensors embedded in, or surfaced mounted onto, the PC beam. In addition, a new concept, involving an optical FBG based technique to detect and locate structural damage, such as crack location and depth, is demonstrated.
\end{abstract}

(Some figures in this article are in colour only in the electronic version)

\section{Introduction}

Many advanced sensory and measurement technologies, including ambient vibration [1], modal analysis combined with system identification [2] and optical fiber sensory systems [35], reported in the last decade, have been used to assess the reliability of civil structures. An optical fiber sensory system, specifically fiber Bragg grating (FBG) sensors, has been developed and has proven to have excellent long-term stability and a high reliability in strain and temperature measurements. In order to fulfill the monitoring needs of a large structure, a fiber optic sensory system can provide many sensor locations with minimum processing requirements. Civil structures must resist environmental and in-service loads such as wind, earthquake, traffic, thermal effects, etc; it has been demonstrated that an intelligent sensory system, including optical fiber sensors and conventional transducers that serve as comparative references, is highly effective in monitoring the response of structures under these types of external loads.
Long-term monitoring of the construction stage characteristics of concrete need more investigation, however, such as the curing process, the prestressed process and sustained loading strain measurements. Furthermore, to develop a reliable long-term monitoring system for structural integrity, based on optical fiber sensors, a new method of damage measurement, to locate cracks and their corresponding depth under loading, must be proposed and evaluated.

Current technology allows FBG sensors to be easily fabricated and placed in PC beams through a side exposure technique. Two typical configurations consist of either exposing a small portion of the optical fiber to two interfering beams of UV light or having one UV beam focused through a phase mask. This creates a periodic modulation of the refractive index in the core of an optical fiber. Due to the periodic nature of the index perturbation, only certain discrete optical frequencies will resonate in the structure. Therefore, if broadband light is traveling in the core of the optical fiber, the incident energy at such a resonant frequency will be reflected 
The health monitoring of a prestressed concrete beam by using fiber Bragg grating sensors

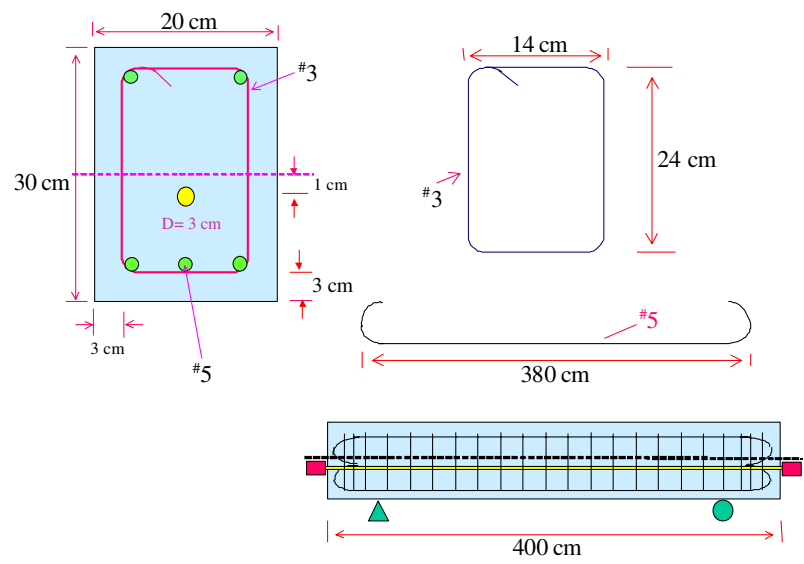

Figure 1. A schematic diagram of the PC beam.

back down the optical fiber. The center wavelength of this resonance condition $[6,7]$ in an FBG sensor can be expressed as

$$
\lambda_{\mathrm{B}}=2 n_{\mathrm{eff}} \Lambda
$$

where $n_{\text {eff }}$ denotes the effective index of refraction of the fiber core, and $\Lambda$ represents the periodicity of the index modulation. As can be seen in equation (1), any change in the periodicity of the refractive index modulation or the overall index of refraction will change the Bragg wavelength. Consequently, any temperature or strain-induced effect on the FBG can be determined by a corresponding shift in the center Bragg wavelength.

The strain is determined by measuring the shift of the Bragg wavelength, $\Delta \lambda$, which is directly related to the axial strain of an optical fiber. From previous experimental studies [7-9], it has been demonstrated that the shift of the Bragg wavelength has a linear relationship to the applied strain in the axial direction.

In this paper, a measurement system that combines both FBG and conventional sensors is utilized to characterize the mechanical behavior of concrete during the curing process. The strain response of a prestressed concrete (PC) beam (see figure 1) under transverse loading conditions, and a method to determine the crack location and depth, are also presented in this study.

\section{Monitoring of the curing process and experimental setup}

Fresh concrete is in a liquid phase before hardening. It is difficult to measure the plastic shrinkage strain of cement paste in its early curing stages using conventional methods [3]. The strain gauge or displacement meter, used to measure the plastic shrinkage strain of the fresh concrete, cannot be attached to the concrete before a certain amount of hardening has taken place. Shrinkage strains, therefore, are usually measured at the time of demolding. In this study, an FBG strain and temperature sensor was mounted on a steel reinforcement area, located $3 \mathrm{~cm}$ above the bottom surface of the PC beam.

The PC beam, with dimensions of $400 \mathrm{~cm} \times 20 \mathrm{~cm} \times$ $30 \mathrm{~cm}$, as illustrated in figure 1, was made of self-compacting concrete (SCC), prestressed steel tendons and mild steel

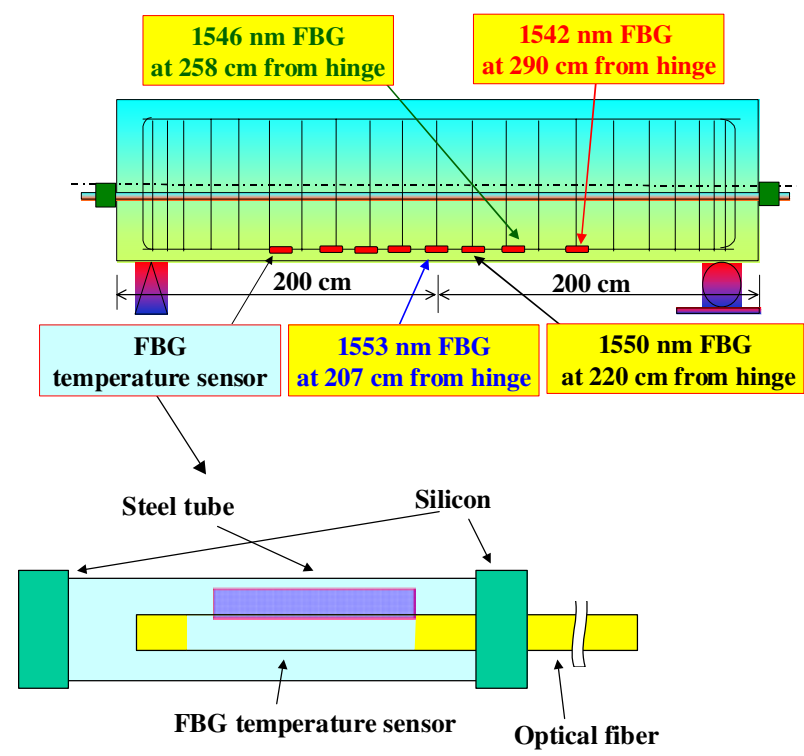

Figure 2. The locations of the FBG sensors in the PC beam

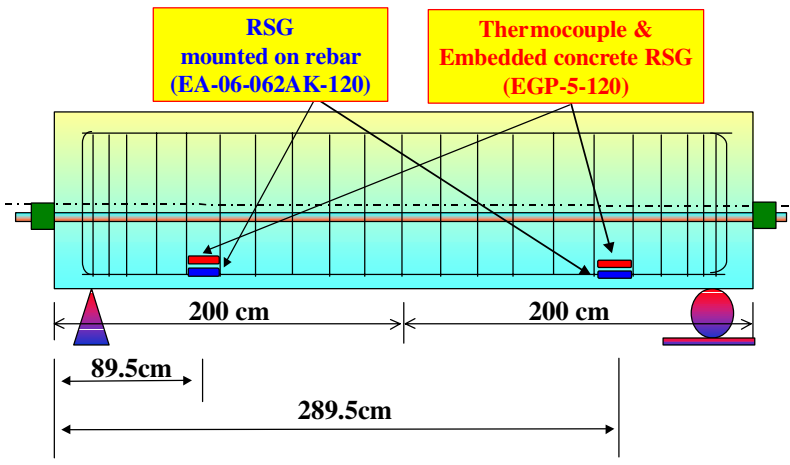

Figure 3. The locations of the thermocouples and the RSG sensors in the PC beam.

reinforcements. Of note is the fact that all the optical fibers were protected in a loose sleeve to prevent damage during the casting and alkali attack stages. However, the wavelength shift, the temperature and the strain cannot be measured simultaneously with a single grating, since there is only one sensing parameter in this application. In order to separate the strain response from the temperature signal, the FBG temperature sensor, shown schematically in figure 2 , was put in a $1 \mathrm{~mm}$ diameter steel tube, sealed with silicone at both ends, to allow stress-free displacement of the temperature deformation of the FBG. This sensor was utilized to measure the temperature inside the $\mathrm{PC}$ beam.

For comparison, concrete strain gauges and thermocouples (figure 3) were embedded in the PC beam. The resistant type strain gauges (RSG) were also placed on the reinforcement, in close proximity to the FBG sensors. In addition, a reference thermocouple was used to monitor the ambient temperature.

Figure 4 shows a typical hydrated reaction temperature during the hardening process. About $6 \mathrm{~h}$ after the concrete casting, hydration begins, and the temperature continues to increase, until reaching approximately the $22 \mathrm{~h}$ stage. As can be seen in figure 4 , between 6 and $14 \mathrm{~h}$ after casting, the 


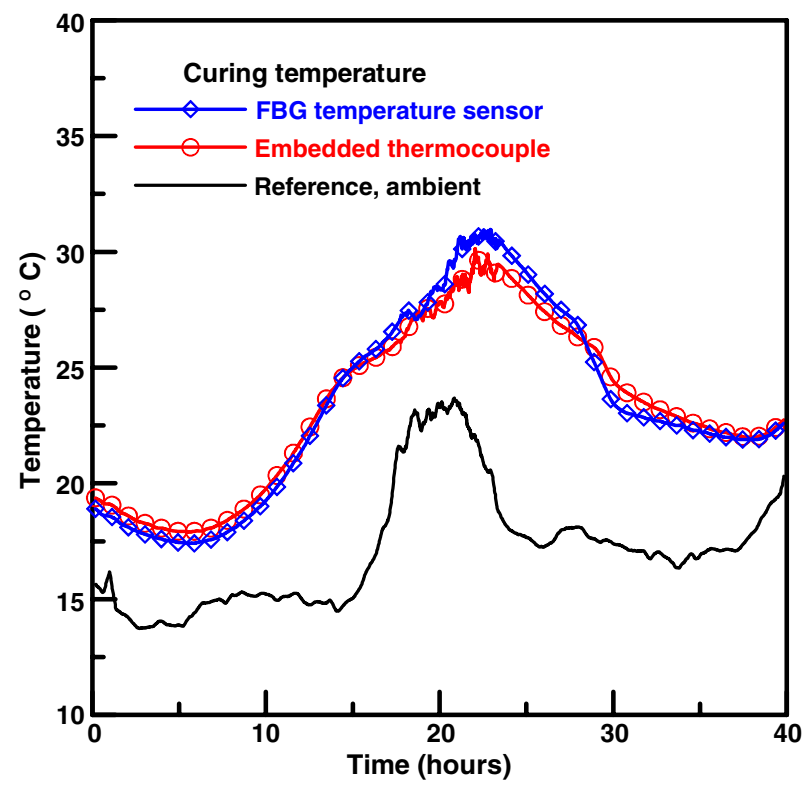

Figure 4. A schematic diagram of the hydrated reactions.

ambient temperature remained steady, while the temperature of the concrete increased up to $25^{\circ} \mathrm{C}$ due to the hydration. When the concrete reached about $25^{\circ} \mathrm{C}$, the rising slope of the temperature changed, due to the change in ambient temperature. During this period, the ambient temperature increased from 15 to $24^{\circ} \mathrm{C}$, which significantly influenced the hydration temperature of the specimen. Figure 4 shows that the peak temperature of the concrete, measured by both the embedded thermocouple and the FBG, was about $31^{\circ} \mathrm{C}$, which implies that the ambient temperature, which reached its peak value about $2.8 \mathrm{~h}$ prior to that of the concrete, had a significant influence. A close correlation $\left(1 \mathrm{~nm} \cong 100^{\circ} \mathrm{C}\right)[4]$ between the thermocouple and the FBG temperature sensor was obtained, indicating the suitability of the FBG application in understanding the hydration process of concrete during hardening.

\section{Strain measurements under axial prestressed and sustained loading}

The feasibility of using the FBG sensory system in this structural integrity study is described below. The tendon in the PC beam was pre-tensioned, by a load cell and actuator, to a desired prestress level for study. For each prestress level, the axial load was fixed by anchoring the end with a steel plate and sleeve, designed with a spiral bearing for anchorage. For strain measurements under axial prestressed loading, five resistance-type strain gauges, $(60 \mathrm{~mm}$ gauge length, EA-0640CBY-120, Measurements group, Inc.) were attached to the concrete surface, $3 \mathrm{~cm}$ above the bottom surface (figure 5) of the beam, to serve as a reference for comparison. Figure 6 displays the locations of the FBG sensors mounted on tendons. A total of 15 FBG sensors were surface mounted on the PC beam.

Figures 7-9 show that good linear correlations between the surface-mounted RSG and FBG sensors were obtained for the PC beam under axial prestressed loading. However,

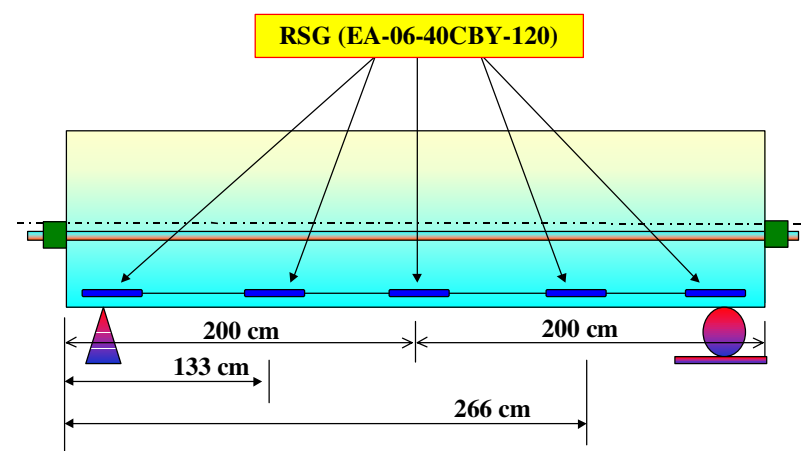

Figure 5. Diagram of the RSG sensors on the PC beam-surface mounted.

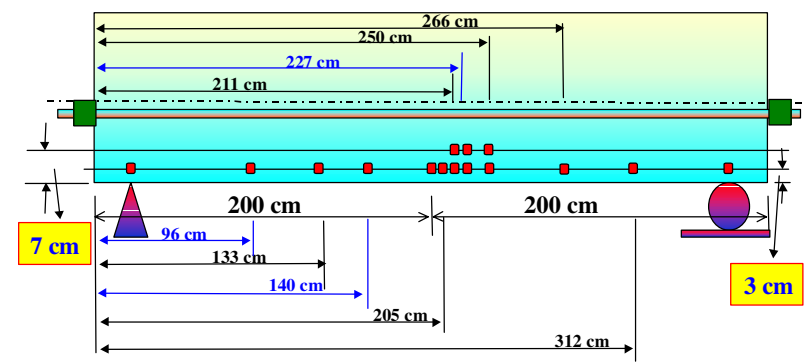

Figure 6. A schematic diagram of the FBG sensors on the PC beam-surface mounted.

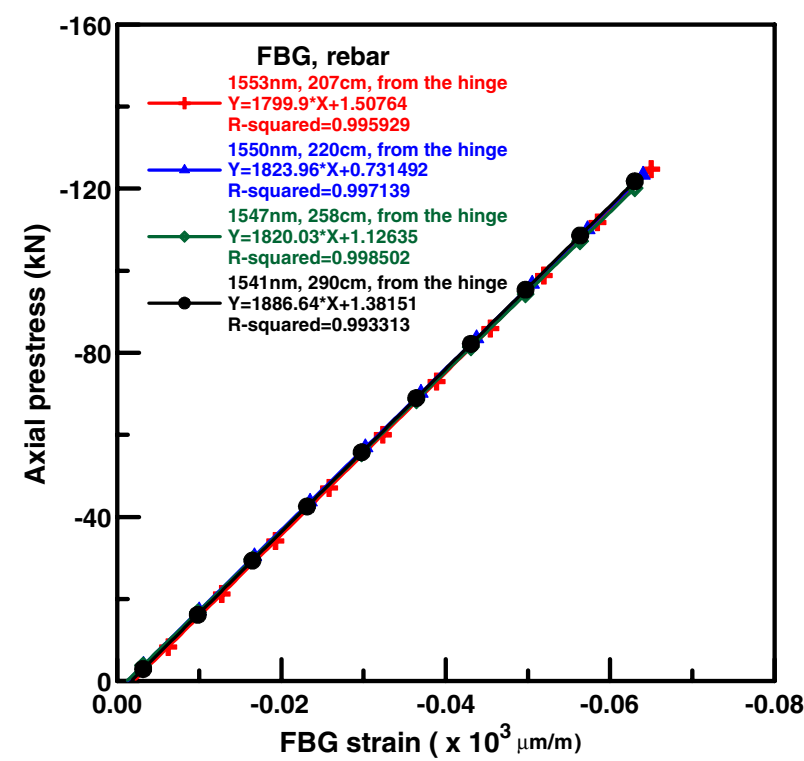

Figure 7. The strain response of the FBG sensors under axial prestress on the rebar.

owing to the short gauge length of the FBG sensors $(<10 \mathrm{~mm})$, when they were surface mounted onto the concrete beam, their strain responses appeared to be slightly scattered (figures 8 and 9) compared to those of the strain gauges. This is because the properties of the material at the concrete's surface were not uniform, because of the mixed coarse and fine aggregate. There was a different strain response between coarse aggregate $(\cong 25 \mathrm{~mm}>10 \mathrm{~mm}(\mathrm{FBG}))$ and fine aggregate, from the mounted FBG sensors. The $R$-squared strain response of the FBG sensors attached to the rebar in the PC beam was about 


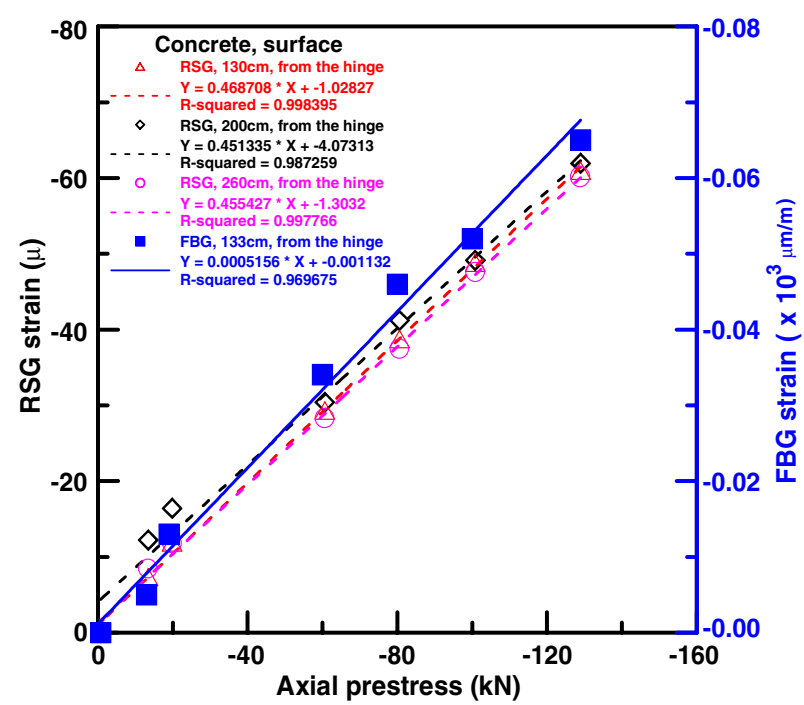

Figure 8. The strain response of the RSG and the FBG sensor under axial prestress on the PC beam.

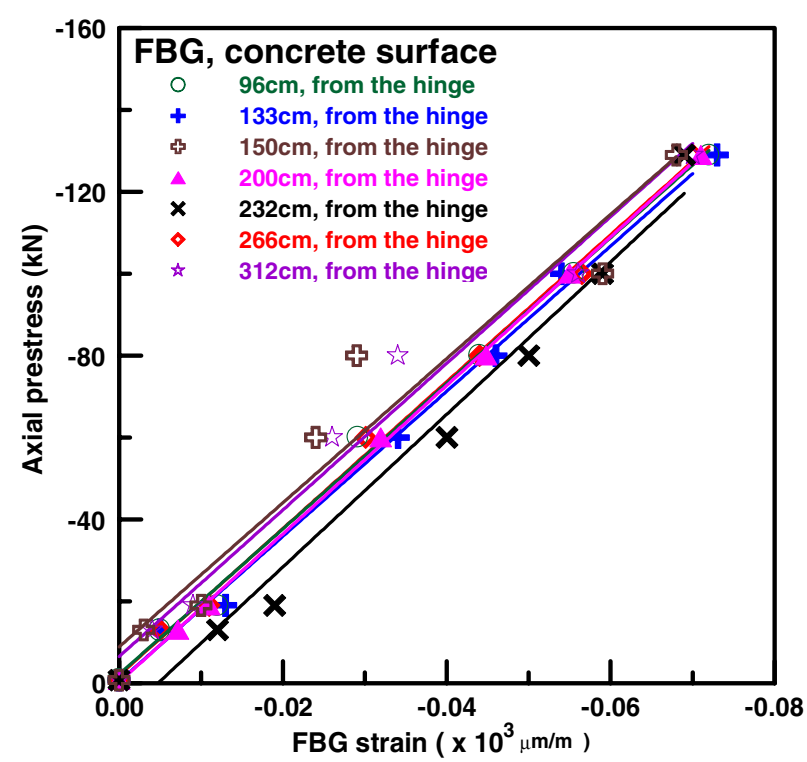

Figure 9. The strain response of the FBG sensors under axial prestress on the PC beam.

0.99, while those mounted on the surface of the PC beam were between 0.969 and 0.945 . This test result reveals that the gauge length of FBG sensors should be at least two or three times longer than the size of the coarse aggregate, in order to get a good averaged value [4].

To monitor the structural response under external loading, a pure bending test setup was chosen. Two $20 \mathrm{~cm} \times 30 \mathrm{~cm}$ rubber pads, under a $120 \mathrm{~cm} \times 30 \mathrm{~cm}$ I-beam was used to apply vertical forces to the test specimen (figure 10). A dial gauge was attached to the I-beam to measure the relative displacement between the I-beam and the PC beam. Such an experimental setup can perform static measurements with good stability for long-term experiments. The location of the sensors and the vertical loading system are illustrated in figures 10-12.

Figure 13 illustrates the response of the RSG sensors, embedded in or surface mounted on the PC beam, and the

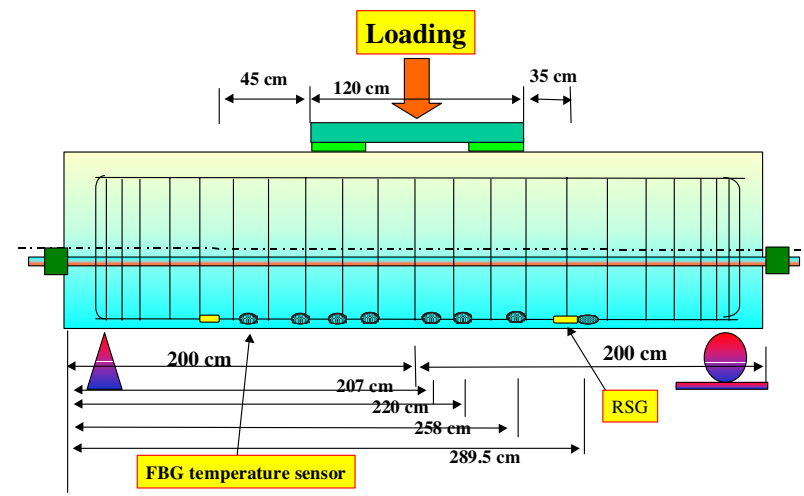

Figure 10. The locations of the FBG sensors and the RSG sensors on the rebar under vertical loading.

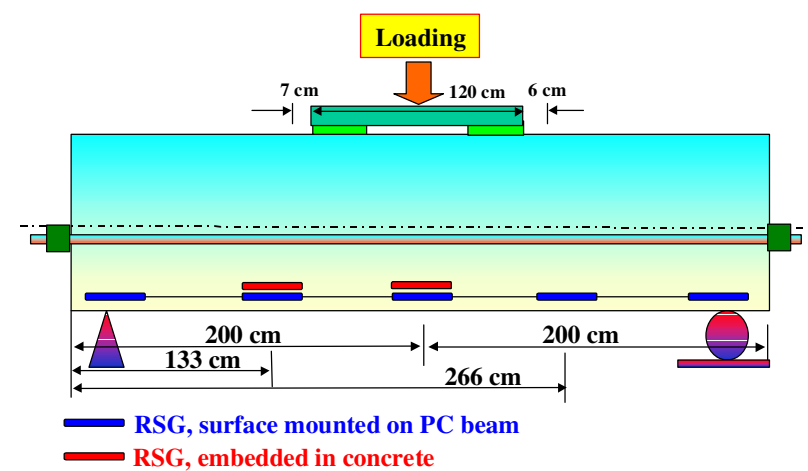

Figure 11. The locations of the RSG sensors under vertical loading.

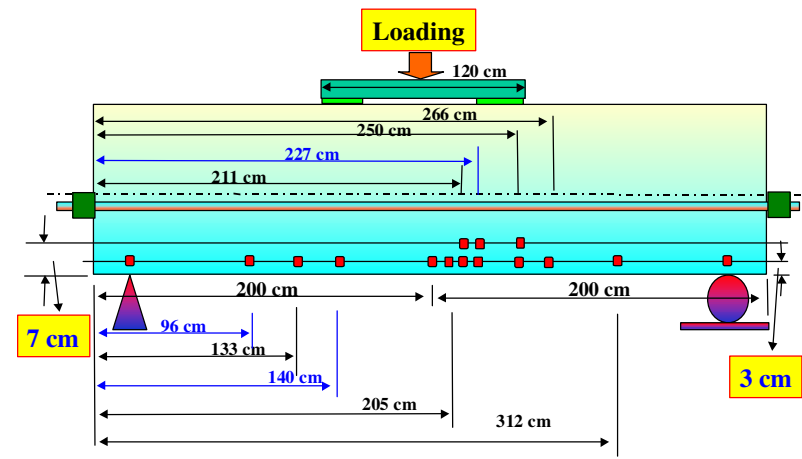

Figure 12. The locations of the FBG sensors under vertical loading on the PC beam.

FBG sensors, mounted on the rebar. As discussed earlier, the strains and wavelength shifts, under pure bending, closely corresponded to each other at the same locations.

As mentioned earlier, for the long-term monitoring of structural integrity, the reliability, durability and accuracy of a sensory system is critical. Figure 14 shows the comparisons between the RSG and FBG sensors, under sustained loading conditions. Obviously, the structural response can be calculated according to the strain measurements shown in figure 14. The immunity of the FBG sensors to electromagnetic noise was also determined and compared to the RSG sensors, as shown in figure 14 . 


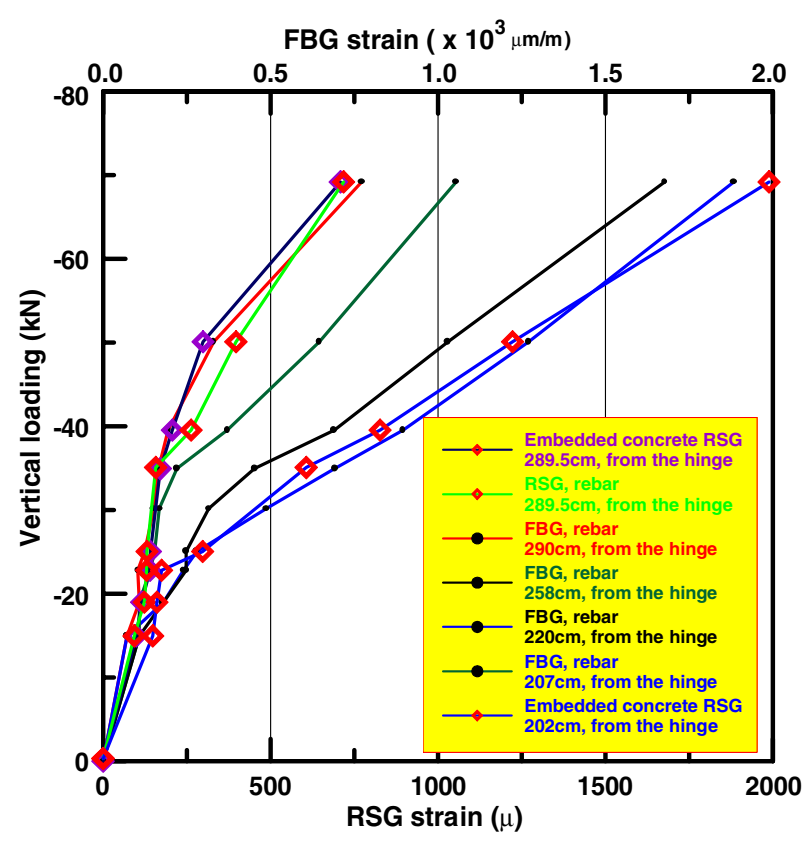

Figure 13. The comparison of strain response between the RSG and the FBG sensors under vertical loading.

\section{Crack monitoring}

It was estimated that the $\mathrm{PC}$ beam initially cracked at a vertical loading of around $21.8 \mathrm{kN}$, under $100 \mathrm{kN}$ axial prestressed loading; the concrete compressive strength was 10000 psi for this PC beam that had cured for 90 days.

The damage to the PC beam, under external loading, is shown in figure 15. As can be seen, as the cracks propagated, they cut across the sensors. When the applied loading exceeded the fracture limit, the initiated cracks damaged or split the RSG and FBG sensors. Meanwhile, the location of the damage or cracks could be assessed from the response of the RSG or FBG sensors, since these gauges did not function properly due to the cracks. Owing to noise and electromagnetic emergence, the RSG was occasionally inactive and induced mistakes. The FBG sensors, based on a silica material, which does not corrode and is not affected by electromagnetic interference, were used as a series of sensors along a single optical fiber. In this way, the location of damage or cracks could be determined directly.

Figure 16 reveals that the FBG sensor (point $\mathrm{B}$, in figure 17), with a wavelength of $1550 \mathrm{~nm}$, was damaged under the applied loading, at around $70 \mathrm{kN}$. Signals between point A and $\mathrm{C}$ (the FBG sensor at point B had not been functioning properly) revealed that the signals of the 1550 and $1553 \mathrm{~nm}$ wavelengths went undetected. To determine if point B was damaged or cracked, the reflection signal between points $\mathrm{B}$ and $\mathrm{C}$ was reconfirmed, and a wavelength of $1553 \mathrm{~nm}$ was obtained.

A similar way to assess crack locations can be used when cracks or damage occur between any two gauges (e.g. between the gauges of 1550 and $1553 \mathrm{~nm}$ ). The wavelengths of 1540 , 1545 and $1550 \mathrm{~nm}$ can be obtained from point A, while the signal of $1553 \mathrm{~nm}$ can be reconfirmed from point $\mathrm{C}$ (see figure 17). When a line of FBG sensors is embedded in a structure, a similar method can be used to detect possible locations of cracks between them.

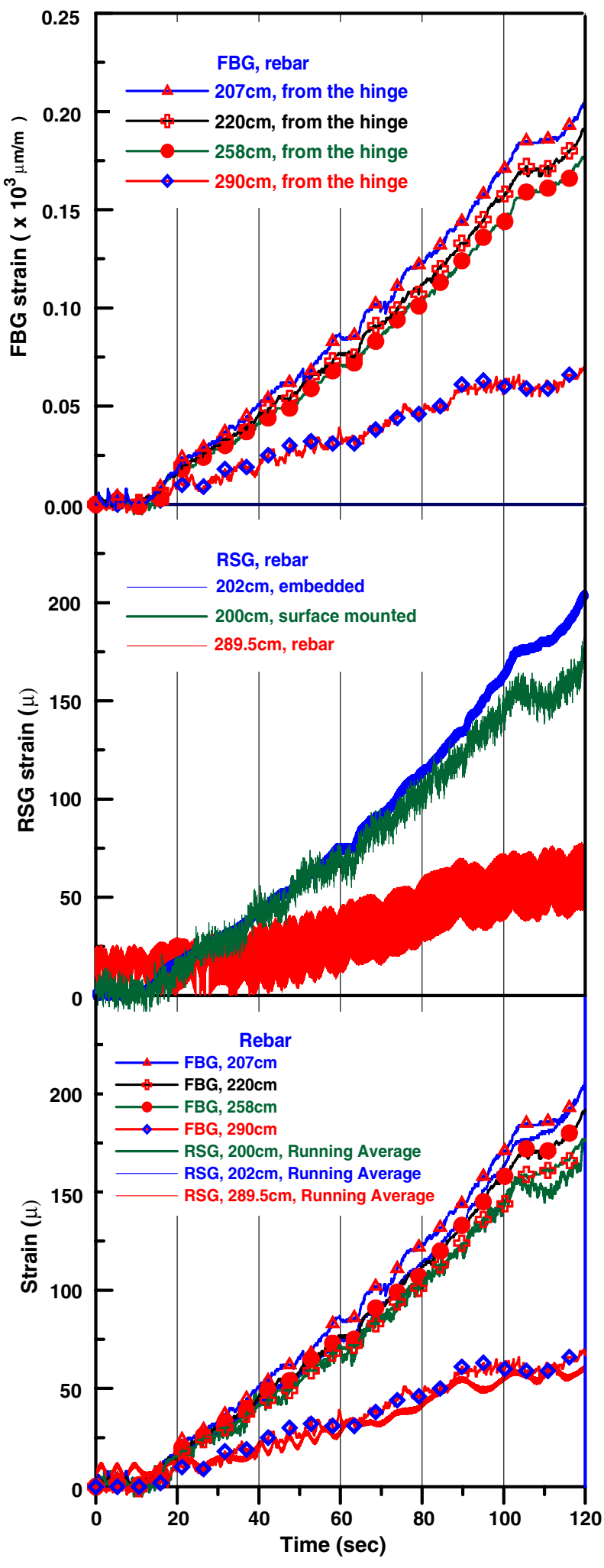

Figure 14. The comparison of the strain response between the RSG and the FBG sensors under real-time measurement at different locations

The depth measurement of the cracks is illustrated in figures 18 and 19. The FBG sensors were surface mounted on the concrete, at 3 and $7 \mathrm{~cm}$ above the bottom surface of the PC beam, respectively. The FBG sensor, located $211 \mathrm{~cm}$ from the 
The health monitoring of a prestressed concrete beam by using fiber Bragg grating sensors

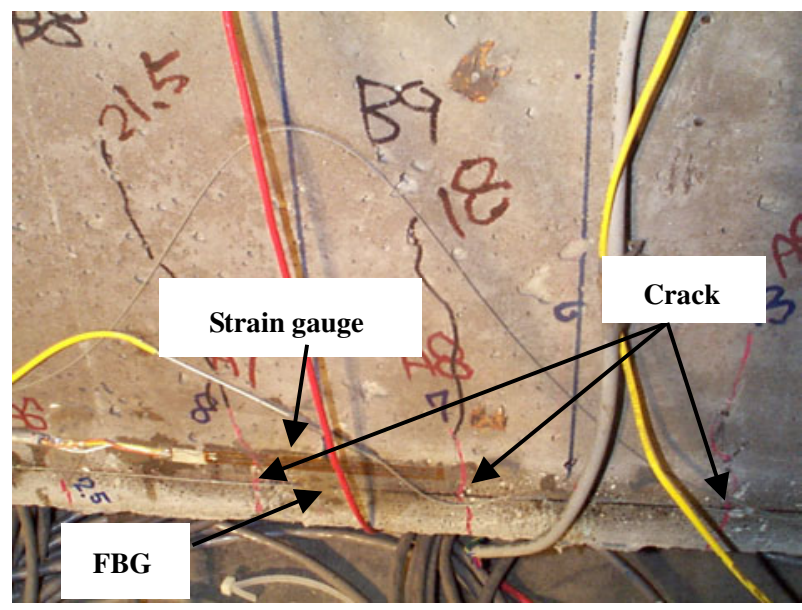

Figure 15. A picture showing a crack crossing the RSG and FBG sensors.

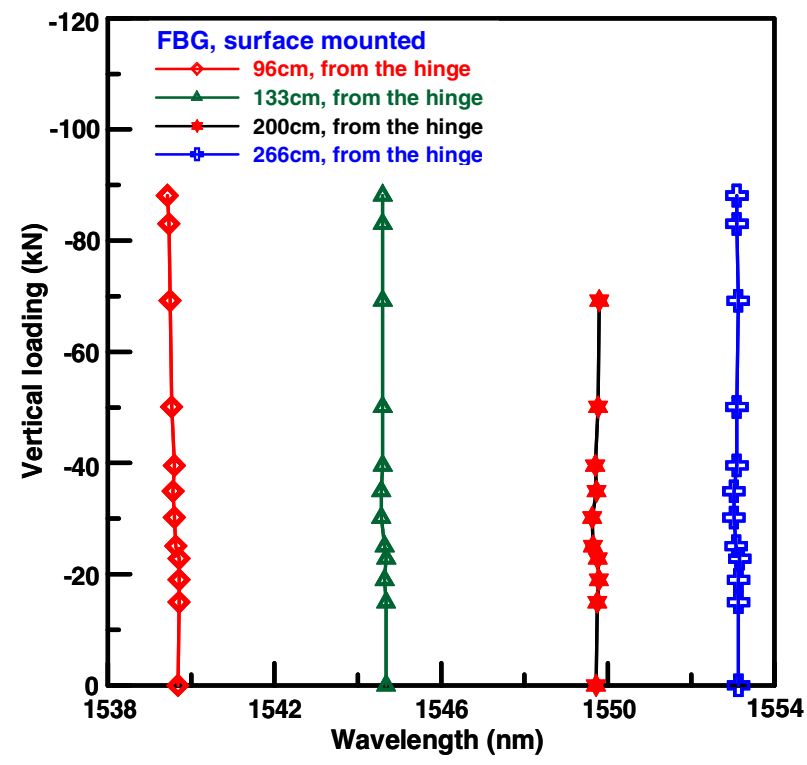

Figure 16. A schematic diagram of the use of the FBG sensors mounted on the PC beam to monitor the crack under vertical loading.

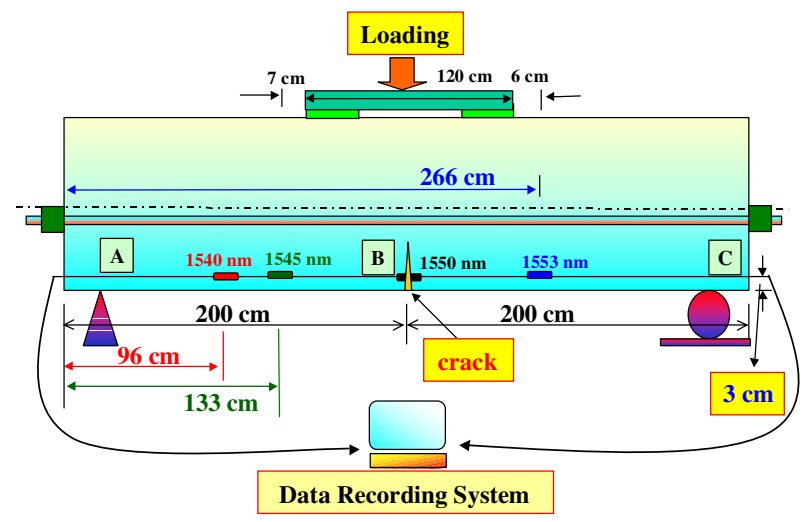

Figure 17. A schematic illustration of the transmission-reflection data recording method and the location of the crack.

support and $3 \mathrm{~cm}$ above the bottom surface of the beam, failed due to cracking when the vertical loading exceeded $30 \mathrm{kN}$

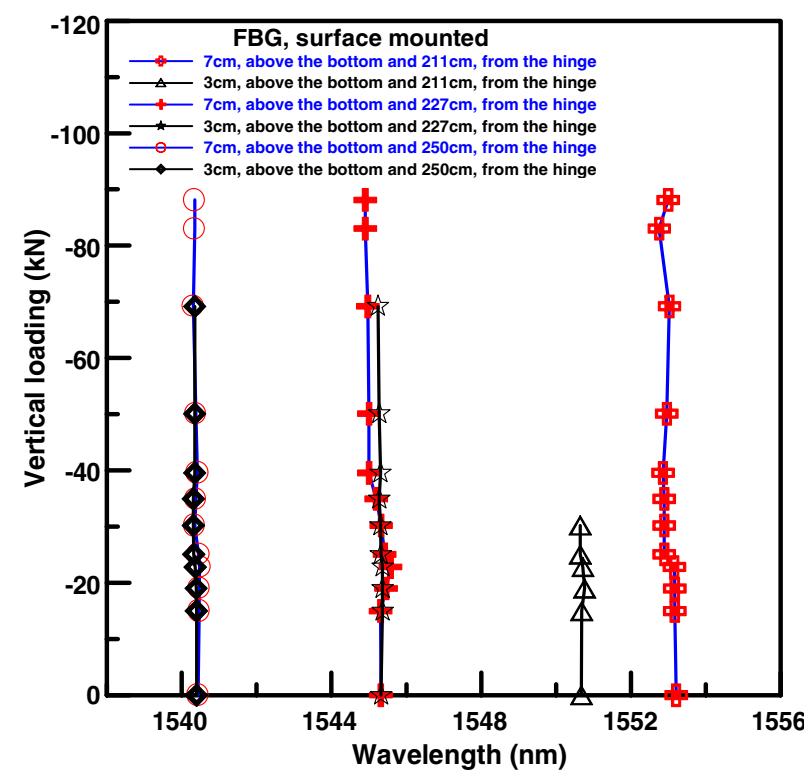

Figure 18. The experimental results of crack depth measurement under vertical loading.

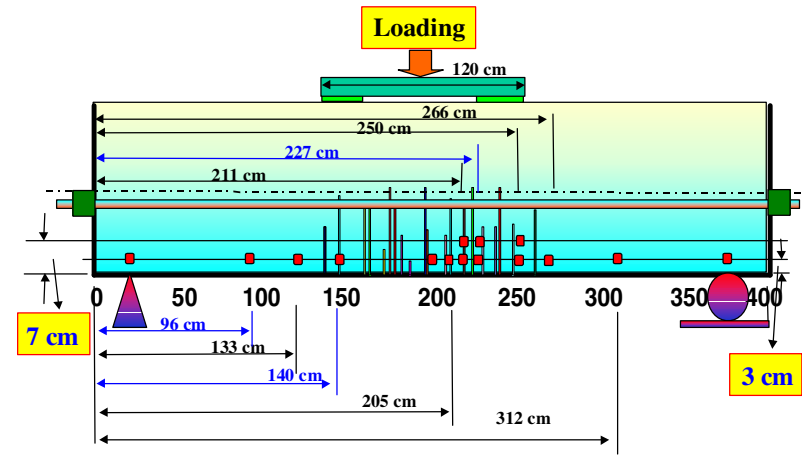

Figure 19. The locations of the FBG sensors and the cracks on the PC beam.

(figure 18). However, the FBG sensor at the same location ( $211 \mathrm{~cm}$ from the hinge), but $7 \mathrm{~cm}$ above the bottom surface of the beam, was still working. It can be concluded, therefore, according to figure 18, that the FBG sensors (at 211, 227 and $250 \mathrm{~cm}$, from the support, respectively), as a network mesh, mounted at different locations and distinct heights, can be used to detect and estimate the depth of cracks.

The test results of the depth of the cracks, and the corresponding location of the 15 FBG sensors surface mounted on the PC beam, are shown in figure 19 as a schematic summary. The wavelength shifts of the FBG sensors were expected to increase with increasing deformation under loading. The wavelength shifts of the sensors decreased, however, with cracking depth (see figures 16 and 18). This can be explained as follows. As structural cracking occurs, the local tension strain nearby is released. Because the FBG sensors are small and localized, they can measure the released strain when the crack opens, and the resultant shift in wavelength. In conclusion, the FBG sensors that were either embedded in or surface mounted onto the concrete, were able to monitor the damage as the structure cracked.

However, among the particles of heterogeneous concrete material, which is composed of coarse and fine aggregate, 
there are irregular and random interfaces. The fracture mechanics of concrete cracks is quite different from those of homogeneous materials, such as metal or its corresponding alloys. Initial (pre-load) micro-cracks are most frequently located at the cement matrix/aggregate interfaces, which are randomly orientated with respect to the load direction [10-18]. The corresponding direction and depth of the propagation of microcracks are difficult to measure or predict. In addition, concrete is a porous and brittle material, and when it is subjected to increasing loads, microcracks are generated within the material, where the loading strain is released, responding to the loading and unloading characteristics. Moreover, the gauge length of the FBG sensor must be considered, since its length is usually less than $10 \mathrm{~mm}$, which is quite small, compared to the dimension of coarse aggregate, which is always larger than $25 \mathrm{~mm}$. These properties make it difficult for the FBG sensors to precisely quantify the actual width or damage growth rates of cracks when they are surface mounted on the PC beam. In this paper, the location and the depth of cracks in a PC beam subject to loading were detected by FBG sensors and corroborated by missing wavelength signals. This proposed non-destructive evaluation (NDE) method can also be applied using Brillouin optical time domain reflector (BOTDR) technology.

\section{Conclusion}

In this paper, FBG sensors, successfully multiplexed in series along a signal fiber, were embedded in or surface mounted onto a PC beam to measure strain and temperature during curing and prestress conditions. The strain induced by the plastic shrinkage of concrete during the hardening process, which manifests itself as a unique application for FBG sensors, was also characterized.

The experimental results indicate that FBG sensors can be used to qualitatively monitor the structural integrity, from the time of concrete casting, through the material's service life. Moreover, a novel technique, to detect and locate structural damage, based on evaluating the signals from FBG sensors, was successfully demonstrated. The test results, obtained by suitable placement of a network of FBG sensors, allowed us to detect the location and depth of cracks when the structure was subjected to heavy loading.

\section{References}

[1] Nakamura M, Masri S, Chassiakos A G and Caughey T K 1998 Neural network approach to damage detection in a building from ambient vibration measurements Symp. on Smart Materials, Structures; Proc. SPIE 3321 126-37
[2] Zhang Z and Aktan A E 1998 Application of modal flexibility and its derivatives in structural identification Res. Nondestruct. Eval. 10 43-61

[3] Schulz W L, Udd E, Seim J M, Laylor H M and Mcgill G E 1998 Single- and multiaxis fiber-grating-based strain sensors for civil structure applications 4th Pacific Northwest Fiber Optic Sensor Workshop; Proc. SPIE 3489 71-8

[4] Chang K C, Chern J C, Wang L A, Lin Y B and Chen H L 1998 A study of fiber Bragg grating sensors in civil structures J. Chin. Inst. Civil Hydraul. Eng. 10 467-75

[5] Lin M W, Abatan A O and Zhang W M 1998 Crack damage detection of structures using distributed electrical-time-domain reflectometry sensors Smart Structures and Materials 1998: Smart Systems for Bridges, Structures, and Highways; Proc. SPIE 3325 173-80

[6] Chan C C, Jin W, Ho H L, Wang D N and Wang Y 2001 Improvement of measurement accuracy of fibre Bragg grating sensor systems by use of gas absorption lines as multi-wavelength references Electron. Lett. 37 742-3

[7] Zhang Y, Feng D, Liu Z, Guo Z and Dong X 2001 High-sensitivity pressure sensor using a shielded polymer-coated fiber Bragg grating IEEE Photon. Technol. Lett. 13 618-9

[8] Murphy D F, Flavin D A and McBride R 2001 Interferometric interrogation of in-fiber Bragg grating sensors without mechanical path length scanning J. Lightwave Technol. 19 1004-9

[9] Lim J, Yang Q P, Jackson P R and Jones B E 2002 Strain and temperature sensors using multimode optical fiber Bragg gratings and correlation signal processing IEEE Trans. Instrum. Meas. 51 622-7

[10] Carpinteri A, Chiaia B and Cornetti P 2003 On the mechanics of quasi-brittle materials with a fractal microstructure Eng. Fract. Mech. 70 2321-49

[11] Duan K, Hu X and Wittmann F H 2003 Boundary effect on concrete fracture and non-constant fracture energy distribution Eng. Fract. Mech. 70 2257-68

[12] Van Mier J G M and Van Vliet M R A 2003 Influence of microstructure of concrete on size/scale effects in tensile fracture Eng. Fract. Mech. 70 2281-306

[13] Li O S, Fang J O, Liu D K and Tang J 2003 Failure probability prediction of concrete components Cement Concrete Res. 33 1631-6

[14] Prado E P and Van Mier J G M 2003 Effect of particle structure on mode I fracture process in concrete Eng. Fract. Mech. 70 1793-807

[15] Kuna-Ciskal H and Skrzypek J J 2004 CDM based modelling of damage and fracture mechanisms in concrete under tension and compression Eng. Fract. Mech. 71 681-98

[16] Yang Z and Chen J 2004 Fully automatic modelling of cohesive discrete crack propagation in concrete beams using local arc-length methods Int. J. Solids Struct. 41 801-26

[17] Yang Z J and Proverbs D 2004 A comparative study of numerical solutions to non-linear discrete crack modelling of concrete beams involving sharp snap-back Eng. Fract. Mech. 71 81-105

[18] Carpinteri A and Spagnoli A 2004 A fractal analysis of size effect on fatigue crack growth Int. J. Fatigue 26 125-33 